\title{
ARDUINO BABY MONITORING WITH TELEGRAM BOT AND WIFI CONNECTION
}

\author{
Muhammad Daffa Akbari ${ }^{1}$ \\ Rusdianto Roestam ${ }^{2}$ \\ President University \\ Bekasi. Indonesia \\ 1daffaakbari29@gmail.com \\ 2rusdianto@president.ac.id
}

\begin{abstract}
The rapid growth of technology has brought the basic needs of human to become easier to be fulfilled. Moreover, in this globalization era, the use of Smartphone and Internet of Things (IOT) has become common things in daily life. This advancement in technology could be applied in accommodating people's necessity. One of the common cases to be found nearby is on how parents could keep their eyes on their children; which could be lacked at times. Sometimes, the children could be out of the parents' reach, especially when it comes to the need of working on daily chores. This research study aims to facilitate the problem faced by most parents in monitoring their children: within the use of technology to monitor the children's activity. This research brought the centralized Wi-Fi network using Telegram application on smartphone which provide automated system that will automatically send notification when the children is crossing their safety line. All system requirements needs to be identified first before planning, design, and developing system. Conducting test will be the last step to make sure the system is working properly.
\end{abstract}

\section{Introduction}

In this short period of time, the development of computer and communications technology is moving very rapidly. Human interest towards technology and curiosity of human to see what else that technology can do. Technology has a big part in this era of modernization that technology already become one to human daily life.

Smartphone has become a part of human daily needs. Smartphones are developed to help human activities starting from education, communication, hobbies, daily activities, until business purposes. It's equipped with advance technology like camera, touch screen, GPS (Global Positioning System), and others.

Nowadays IOT or Internet of Things has become more usual in our life. IOT product is increasing year by year to accommodate people's life to be easier and people's not really bothered by a device that will listen or monitor their life.

In Indonesia, there are still a lot of babies or children accident happen every day because of lack of monitoring by their parents. How to prevent the accident happen just when it is occured or before it is happening. How if parents no need to always monitor their babies or children in the same room or there are automated device that will prevent it even when the Parents are not monitoring their babies..

This research will develop a System with Telegram Bot and Arduino that will help Parents monitor their Kids while they are doing their chores or basically anything. The system can provide photo from where ever the system placed, detects if kids crossing the line (sensor) and automatically sends notification and close or lock the gate and prevent kids to go out or go somewhere that will harm them.

\section{Limitation}

The limitations of this application are as following:

1. The maximum distance depends on the ability of the Wi-Fi router.

2. The maximum processing power and pins in Arduino.

3. The code limitation is the Arduino library.

\section{Method}

This section explains the method used in the development of the application.

\subsection{Microcontroller}

A microcontroller (or MCU for microcontroller unit) is a small computer on a single integrated circuit. A microcontroller contains one or more CPUs (processor cores) along with memory and programmable input/output peripherals. 
Microcontrollers are used in automatically controlled products and devices, such as automobile engine control systems, implantable medical devices, remote controls, office machines, appliances, power tools, toys and other embedded systems. By reducing the size and cost compared to a design that uses a separate microprocessor, memory, and input/output devices, microcontrollers make it economical to digitally control even more devices and processes. (Augarten, 1983)[2].

\subsection{Arduino}

Arduino is an open-source physical computing platform based on a simple input/output (I/O) board and a development environment that implements the Processing language. Arduino can be used to develop standalone interactive objects or can be connected to software on the computer such as Flash. Arduino is composed of two major parts; the Arduino board, the piece of hardware to work on, and the Arduino IDE, the piece of software to run on the computer. (Arduino, 2019)[1]. There are many versions of board, Arduino UNO is the example shown in Figure 1.

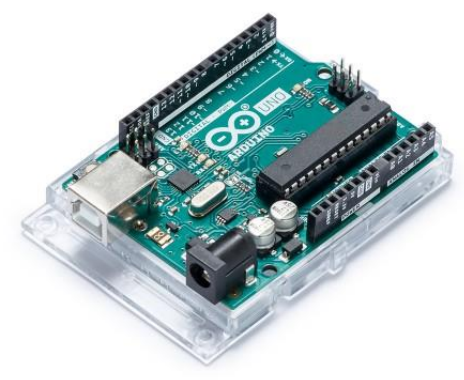

Figure 1. Arduino Uno

\subsection{ESP8266 Wi-Fi Module}

ESP8266 as shown in figure II.2 is a system-onchip (SoC) which integrates a 32-bit Tensilica microcontroller, standard digital peripheral interfaces, antenna switches, RF balun, power amplifier, low noise receive amplifier, filters and power management modules into a small package.

It provides capabilities for $2.4 \mathrm{GHz}$ Wi-Fi (802.11 b/g/n, supporting WPA/WPA2), generalpurpose input/output (16 GPIO), Inter-Integrated Circuit $\left(\mathrm{I}^{2} \mathrm{C}\right)$, analog-to-digital conversion (10-bit ADC), Serial Peripheral Interface (SPI), I ${ }^{2} S$ interfaces with DMA (sharing pins with GPIO), UART (on dedicated pins, plus a transmit-only
UART can be enabled on GPIO2), and pulsewidth modulation (PWM). The processor core, called "L106" by Espressif, is based on Tensilica's Diamond Standard 106Micro 32-bit processor controller core and runs at $80 \mathrm{MHz}$ (or overclocked to $160 \mathrm{MHz}$ ).

It has a $64 \mathrm{KiB}$ boot $\mathrm{ROM}, 32 \mathrm{KiB}$ instruction RAM, and $80 \mathrm{KiB}$ user data RAM. (Also, 32 $\mathrm{KiB}$ instruction cache RAM and $16 \mathrm{KiB}$ ETS system data RAM.) External flash memory can be accessed through SPI. The silicon chip itself is housed within a $5 \mathrm{~mm} \times 5 \mathrm{~mm}$ Quad Flat NoLeads package with 33 connection pads -8 pads along each side and one large thermal/ground pad in the center (esp8266, 2019)[3]. The module is shown in figure 2 .

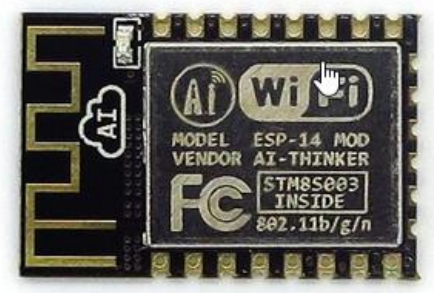

Figure 2. ESP8266

\subsection{Telegram API}

Telegram is a mobile messaging platform. Telegram offers highly encrypted messaging services so users can send messages, photos, and videos to selected contacts privately. The Telegram API allows developers to access and integrate the functionality of Telegram with other applications. Some example API methods include managing contacts, checking phones, and sending and retrieving messages, photos, and videos (Programmable, 2019)[4].

\subsection{Use Case Diagram}

In this application there are 3 actors that are parents, baby, and Arduino. The main activity in this application are to monitor the baby and prevent the baby to go beyond the sensor.In this application. In addition, this application's usecase diagram will be shown in Figure 4. 


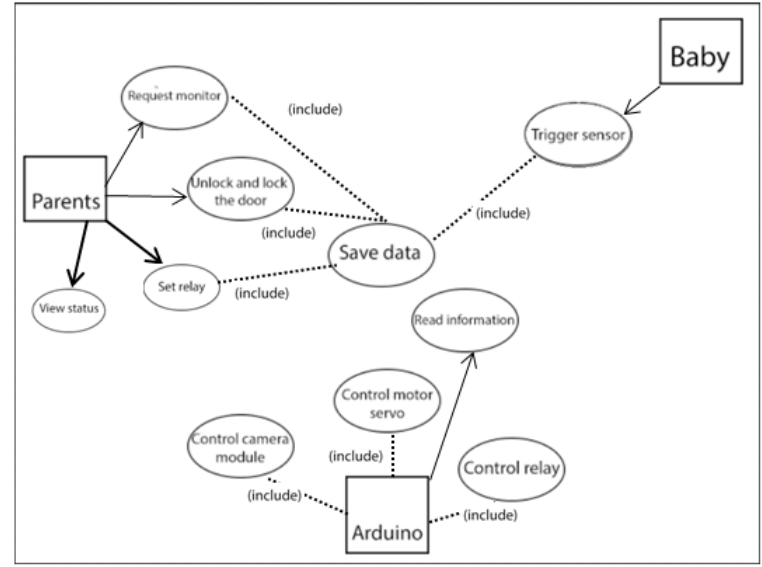

Figure 3. Use Case Diagram

\section{Experimental Result}

This section describes the testing and results of this research. Figure 5 shows the Home Page from the Telegram chat to control the camera and lock mechanism Table 1 shows the Arduino result.

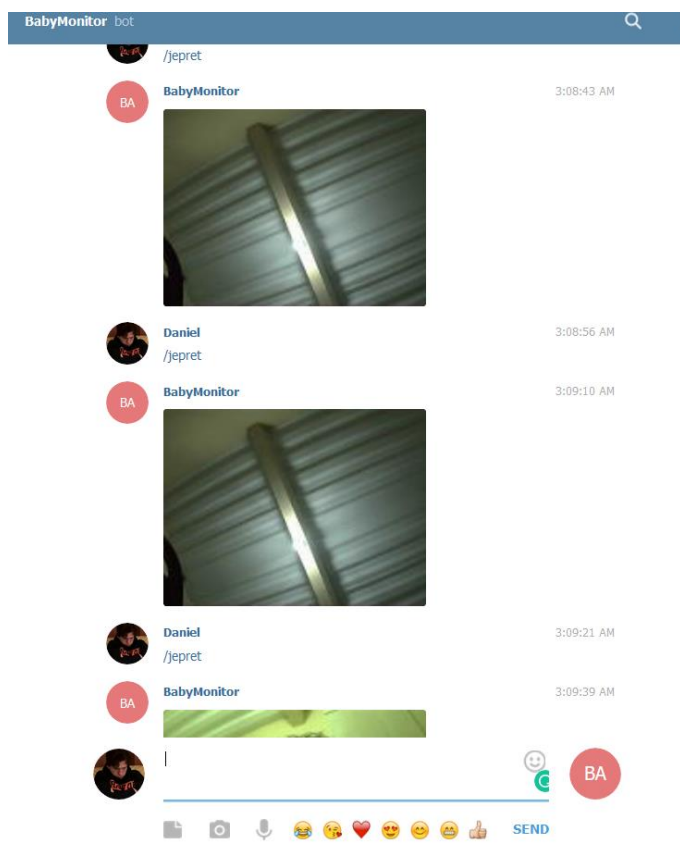

Figure 4. Home Light Monitoring and Controlling Application

Testing scenario describes the activities to be tested in order to ensure proper functioning of the system and application.
The Arduino Baby Monitoring with Telegram Bot and $\mathrm{Wi}-\mathrm{Fi}$ Connection test scenario is divided into four separate sections:

- To take picture and send to Telegram chat

- To determine whether the baby outside the safe zone and trigger the motor

- To manually trigger the motor

- To manually trigger the relay module

Table 1. Evaluation of the Home Light Monitoring and Controlling Application

\begin{tabular}{|c|l|l|}
\hline No & Scenario & \multicolumn{1}{|c|}{ Evaluation } \\
\hline 1. & $\begin{array}{l}\text { Take picture and } \\
\text { send to telegram } \\
\text { chat }\end{array}$ & $\begin{array}{l}\text { The system reads from } \\
\text { Telegram chat if } \\
\text { monitor command is } \\
\text { sent and trigger the } \\
\text { camera module and } \\
\text { send the picture to } \\
\text { Telegram chat. }\end{array}$ \\
\hline 2. & $\begin{array}{l}\text { Determine } \\
\text { whether the baby } \\
\text { outside the safe } \\
\text { zone and trigger } \\
\text { the motor }\end{array}$ & $\begin{array}{l}\text { The system with IR } \\
\text { obstacle module sense } \\
\text { if the baby close to } \\
\text { module and trigger the } \\
\text { motor to turn the lock } \\
\text { mechanism. }\end{array}$ \\
\hline 3. & $\begin{array}{l}\text { Manually trigger } \\
\text { the motor }\end{array}$ & $\begin{array}{l}\text { The system reads from } \\
\text { Telegram chat if lock } \\
\text { or unlock command is } \\
\text { sent and trigger the } \\
\text { motor to turn the lock } \\
\text { mechanism to desired } \\
\text { state. }\end{array}$ \\
\hline 4. & $\begin{array}{l}\text { Manually trigger } \\
\text { the relay module }\end{array}$ & $\begin{array}{l}\text { The system reads from } \\
\text { Telegram chat if the on } \\
\text { or off command for } \\
\text { relay is send and trigger } \\
\text { the relay to desired } \\
\text { state. }\end{array}$ \\
\hline
\end{tabular}

\section{Discussion}

This section presents discussion about the effectiveness of Arduino Baby Monitoring with Telegram Bot and Wi-Fi Connection, which are:

- User can take picture and receive the picture from Telegram chat

- The motor could automatically turn to lock position by the sensor of IR obslacle sensor.

- User can manually lock and unlock the door 
IT FOR SOCIETY, Vol. 04, No. 02

ISSN 2503-2224

- User can manually turn on or off the relay module

\section{Conclusion}

After having the result of conducting the testing from the implementation the Arduino baby monitoring with Telegram bot and Wi-Fi connection it can be said that the application is able to provide help for the parents to monitor their baby this includes:

1. This application equipped with Wi-Fi module (ESP8266) is working properly as the result parents can monitor their baby with Internet connection.

2. The used of IR Obstacle sensor in this system can provide the ability to determine whether the baby is outside the safe zone in addition the system can also provide notification to the parents when the baby crossed the safe zone.

3. This application equipped with Telegram bot as the remote control is working properly as the result parents can control all the function in the system with any devices that can install Telegram application.

\section{References}

[1] Arduino. (2019). What is Arduino? Retrieved 05 13, 2019, from arduino.cc: https://www.arduino.cc/en/Guide/Introduc tion

[2] Augarten, S. (1983). The Most Widely Used Computer on a Chip: The TMS 1000. State of the Art: A Photographic History of the Integrated Circuit. New Heaven and New York: Ticknor \& Fields.

[3 ]esp8266. (2019). What is ESP8266?

Retrieved 05 13, 2019, from esp8266. net: http://esp8266.net/

[4] Programmable. (2019). Telegram API. Retrieved 05 15, 2019, from programmableweb.com: https://www.programmableweb.com/api/t elegram 